\title{
O USO DO AMBIENTE DE APRENDIZAGEM SOCRATES COMO FERRAMENTA DE INTERAÇÃO NO ENSINO DE FÍSICA
}

\section{Francisco Halyson FerReira Gomes}

Instituto Federal de Educação do Ceará

E-mail: halysongomes@yahoo.com.br

\section{FranCISCO RÉGIS VIEIRA ALVES}

Instituto Federal de Educação do Ceará

E-mail: fregis@ifce.edu.br

\section{RESUMO:}

Neste trabalho relatamos a experiência de alunos do ensino médio na participação de fóruns de discussão no Ambiente Virtual de Aprendizagem (AVA) SOCRATES. Nosso objetivo é revelar os aspectos pedagógicos da utilização do SOCRATES. Através deste artigo referenciamos como o uso de AVAs pode ser usado como ferramenta pedagógica no ensino de Física. O uso de redes sociais entre jovens participantes desta pesquisa é uma realidade, seja para interagir com outras pessoas ou para auxiliar nos estudos. A análise das respostas aos fóruns propostos demonstrou que embora existam algumas dificuldades quanto ao uso das ferramentas do AVA e ao entendimento das questões, o SOCRATES é um ambiente que facilita a comunicação, facilitando o ensino de Física ao passo que amplia o espaço da sala de aula.

\section{PALAVRAS-CHAVE:}

SOCRATES; ensino de Física; interatividade.

THE USE OF LEARNIG ENVIRONMENT SOCRATES LIKE INTERACTIVE TOOLS IN PHYSICS TEACHING

\begin{abstract}
:
In this article, we report online forums in Virtual Learning Environment (VLE) SOCRATES by high school students. Our objective is to show pedagogical aspects of the use of the SOCRATES. Through this article, we reference like the use of VLEs can be used as a tool for teaching physics. The use of social networks by people of this research is a reality to talk or help in the studies. The analysis of the forums proposed in this research shows us that some students have difficulties using SOCRATES tools and understanding the questions. The SOCRATES is an environment that facilitates communication between the students. These properties enlarge the time of study class and facilitate the teaching of physics.
\end{abstract}

\section{KEYWORDS:}

SOCRATES; Physics teaching; interactivity. 


\section{INTRODUÇÃO}

Na sociedade contemporânea, diferentes tarefas cotidianas, tais como fazer compras, pagar contas ou até mesmo se comunicar com outras pessoas estão sendo feitas por meio do computador. Até se popularizar este equipamento passou por diferentes etapas de transformação, a miniaturização dos componentes, a evolução dos programas de informática e o desenvolvimento da internet são exemplos de inovações tecnológicas que fizeram com que o computador entrasse na casa das pessoas e pudesse ser utilizado como ferramenta comum.

A escola, local importante na formação das pessoas, precisa estar atenta as inovações tecnológicas. Ao se apropriar de metodologias que inserem o computador nas práticas pedagógicas, o professor pode levar os alunos a desenvolver competências e habilidades que o ajudem no convívio social. A interatividade proporcionada pela internet e o grande volume de informações pode levá-lo a um patamar importante na construção do conhecimento dentro dos processos educacionais.

Neste trabalho buscamos identificar o potencial pedagógico do uso de fóruns de discussão no ambiente virtual de aprendizagem (AVA) SOCRATES para o ensino de Física. Nossos objetivos específicos são a identificação entre alunos participantes do grupo amostral dos interesses em participar de redes sociais virtuais; promover a utilização do SOCRATES como recurso pedagógico na disciplina de Física e avaliar as suas funcionalidades, tomando como parâmetro as atividades propostas em fóruns de discussão.

Este estudo de caso foi realizado com alunos matriculados na 1a série do ensino médio de uma escola da rede pública de ensino, vinculada a 1a Coordenadoria Regional de Desenvolvimento da Escola (CREDE). Durante três meses os alunos participantes 
desenvolveram atividades no espaço denominado fórum dentro do AVA SOCRATES, no qual eles puderam discutir sobre temas ligados à Física.

\section{O COMPUTADOR E A INTERNET NO ENSINO DE FÍSICA}

O início do computador moderno se deu quando Konrad Zuse desenvolveu uma máquina, batizada de Z1, capaz de guardar cálculos intermediários para serem usados em momentos posteriores. Segundo Filho (2007) o desenvolvimento da série Z e o interesse da IBM em desenvolver máquinas eletromecânicas capazes de realizar cálculos foi um passo importante para o aperfeiçoamento tecnológico que resultou na criação do primeiro computador, o ENIAC, no período da segunda grande guerra.

Embora o ENIAC tenha revolucionado o cenário de tecnologia da época, sua operação não era nada fácil. Ainda segundo Filho (2007) era preciso, às vezes, um dia inteiro para programar e executar suas operações. A medida que os avanços tecnológicos na construção de peças cada vez menores e mais eficiente e o desenvolvimento de linguagens computacionais que proporcionam uma agilidade na realização das tarefas transformou o computador num equipamento de uso geral das pessoas.

Outro fato que contribuiu para essa popularização foi a concepção da internet. A ideia de criar a web ou world wide web (www) tinha como base a construção de uma biblioteca multimídia global no qual computadores do mundo todo teriam acesso a textos, imagens, sons e quaisquer outros arquivos disponíveis. O fato das pessoas terem acesso à informação de uma forma muito mais rápida faz com que, segundo Lévy (2000) a produção e disseminação do conhecimento e da forma de interação entre as pessoas sofra forte impacto. Como qualquer outro meio de comunicação a internet é passível de interpretações, ou seja, as mensagens que circulam pela rede de computadores podem produzir efeitos diferentes nas pessoas. As mensagens e seus 
significados se alteram ao deslocar-se de um ator a outro na rede, e de um momento a outro do processo de comunicação (LÉVY, 2000).

Considerando que a internet possibilitou a pessoas a oportunidade de atuarem de forma mais ativa na construção de conhecimento é inegável que a Educação tenha passado por modificações com a introdução do computador e da internet na escola, isto é, Segundo Araújo (2007) a internet funciona como espaço pedagógico, possibilitando a inserção do aluno em diferentes contextos, possibilitando principalmente a oportunidade de interação.

O estudante que utilizar a rede mundial de computadores como fonte de pesquisa será capaz de aprimorar conhecimentos de forma ativa e significativa. Segundo Dias (1999) o hipertexto, como dispositivo didático, provê um ambiente propício à exploração, em que o aluno desenvolve seu próprio estilo cognitivo. Mas como a Física pode se apropriar dessas vantagens para ajudar no entendimento de seus fenômenos?

Um dos objetivos da Física é estimular competências que façam o aluno entender fenômenos naturais e tecnológicos a partir de princípios, leis e modelos bem definidos e para isso devem estar em consonância com fatos da realidade e em articulação permanente com competências de outras áreas do conhecimento (MEC, 2002). Com isso, o ensino de Física ganha uma dimensão mais ampla e o professor precisa fazer uso de múltiplas linguagens para formar pessoas com capacidades mínimas de entendimento sobre essa Ciência.

Segundo Medeiros e Medeiros (2002) uma das dificuldades em ensinar Física é a falta de habilidade do aluno em abstrair, muitas vezes culpa de um currículo desmembrando, no qual são apresentadas situações fora de contexto e enfadonhas. Com a edificação dos Parâmetros Curriculares Nacionais para o ensino médio (PCNs +) a Física passou a ser reconhecida como uma Ciência que deve estimular a identificação 
e entendimento de fenômenos naturais. A Física ganha uma dimensão ampla e o professor precisa fazer uso de múltiplas linguagens para que ocorra uma articulação permanente entre os modelos físicos apresentados em sala de aula e a realidade (MEC, 2002).

Para Vankar apud Medeiros e Medeiros (2002) mesmo existindo dúvidas sobre as vantagens do uso do computador o seu proveito no campo educacional do pensamento lógico da Física seria inquestionável. Ferramentas gráficas, animações, simulações, ambientes de aprendizagem virtual são alguns exemplos das ferramentas que podem ser usadas por professores e alunos dentro de situações didáticas a fim de facilitar o ensino e a aprendizagem em Física.

\section{O AMBIENTE SOCRATES}

O número de redes sociais é muito grande e reúnem pessoas com interesses em comum. Segundo Costa (2005) foi Howard Rheingold um dos pioneiros na criação e desenvolvimento de comunidades virtuais. Dentre essas comunidades podemos citar os ambientes virtuais de aprendizagem (AVA). Um AVA é um espaço composto por uma plataforma de educação a distância e material didático compatível com as atividades a serem desenvolvidas na plataforma (PIRES; VEIT, 2006).

Em 2003, o Ministério da Educação (MEC) criou a Rede Nacional de Centros de Formação Continuada (REDE) com o objetivo de fomentar iniciativas para a formação de professores do ensino médio. A REDE foi composta inicialmente por dezenove universidades, dentre elas a Universidade Federal do Ceará (UFC), que criou o Núcleo de estudos e pesquisas em educação continuada para o desenvolvimento das Humanidades (HUMANAS) que tinha como princípios a pedagogia de projetos. Um dos produtos desenvolvidos pelo HUMANAS foi o Sistema online para a criação de projetos e comunidades (SOCRATES). 
Segundo David et al apud Silva et al (2007) o SOCRATES é um ambiente educacional on-line que dispõe de ferramentas para elaboração e desenvolvimento de projetos colaborativos no contexto escolar e criação de comunidades de aprendizagem. Após a liberação da proposta de trabalho, por parte dos administradores do ambiente, o professor poderá convidar pessoas para participar das atividades.

Dentre as opções para o desenvolvimento das atividades pedagógicas, o professor pode escolher criar uma Comunidade, um Projeto ou um Curso. Em cada categoria o professor terá à disposição diferentes ferramentas para a elaboração de seus trabalhos.

Neste trabalho optamos pela categoria Curso, na qual o professor poderá propor fóruns de discussão, gerenciar o cronograma de atividades da turma, acessar o portfólio dos participantes, acessar o material de referência da turma, propor séries de chats, inserir aulas sobre o tema abordado no curso.

O diferencial da modalidade curso é o acompanhamento do desempenho dos participantes. Por meio dessa ferramenta o professor tem acesso de forma rápida e eficiente ao progresso dos participantes durante o período de duração do curso, como a quantidade de acessos, a quantidade de mensagens e a localização das mensagens de forma individualizada. Um ambiente virtual de aprendizagem pode ser definido como um espaço composto pelos seguintes fatores: uma plataforma de educação a distância e material didático compatível com as atividades a serem desenvolvidas na plataforma (PIRES; VEIT, 2006).

\section{PeRCuRSOS MetOdológicos}

Neste trabalho optou-se em realizar uma pesquisa de estudo de caso que se volta à coleta de informações sobre um ou vários casos particularizados. Segundo Yin (2001) estudo de caso é um estudo de eventos dentro de seus contextos da vida real. 
E, portanto os dados devem ser coletados de pessoas e instituições existentes e não dentro dos limites controlados de um laboratório ou por meio de questionários com uma estrutura rígida.

Neste projeto faremos uma análise quantitativa e qualitativa dos dados. Por meio da aplicação de questionário analisaremos pontos sobre o uso de redes sociais pelos estudantes do nosso grupo amostral bem como quantificamos pontos positivos e negativos quanto a utilização das ferramentas do AVA. Nossa análise qualitativa permitirá fazer um acompanhamento das respostas dos fóruns e verificar a real contribuição dos alunos para a atividade.

Nossa estratégia de acompanhamento dos fóruns se baseia em Gerosa (2003) apud Azevedo et al. (2009) que propõe um acompanhamento de fóruns online através da categorização das mensagens, já que segundo a autora a categorização ajuda a identificar características de cada tipo de mensagem. Neste projeto dividimos as mensagens em duas categorias, a primeira com respostas diretas ao que o professor propôs no início da atividade e a segunda categoria com mensagens de interação.

A análise do conteúdo dos fóruns seguir Bardin apud Silva e Fossá (2013), que divide a análise de conteúdo de uma pesquisa qualitativa em 3 etapas: pré análise, na qual se faz a leitura atenta de todo o material a ser analisado para definir o corpus da análise; exploração do material, cujo objetivo é agregar informações para criação de categorias simbólicas e interpretação no qual é feito um recorte do material com mesmo teor semântico.

Este estudo foi realizado com 40 alunos matriculados na 1a série do ensino médio de uma escola da rede pública de ensino, localizada no município de Maracanaú. O grupo tem faixa etária entre 14 e 18 anos, sendo 11 alunos do sexo masculino e 29 alunos do sexo feminino. 
Dentre as possibilidades de atuação disponibilizadas pelo ambiente SOCRATES a opção escolhida foi a criação e o gerenciamento de um curso. Esta escolha foi baseada na análise das ferramentas oferecidas: fórum, chat, portfólio, acompanhamento de participação, mensagem e publicação de textos no espaço das aulas.

Para o desenvolvimento deste trabalho foram desenvolvidas as seguintes ações: criação do curso no ambiente SOCRATES, aplicação das atividades propostas e coleta e análise dos dados. Estes foram obtidos por meio da aplicação de um questionário e acompanhamento das respostas dadas ao fórum.

Os alunos desenvolveram atividades no espaço denominado fórum no qual os alunos tiveram a oportunidade de discutir sobre um determinado tema ligado à Física. Sanchez (2005) apud Azevedo (2009) defende a ideia que fóruns online com finalidade educacional se firmam como um espaço de diálogo nos quais as mensagens podem ser classificadas por temas. No primeiro fórum os alunos se apresentaram, e em seguida no segundo fórum eles discutiram sobre as concepções de movimento para Aristóteles e Galileu. Todos os encontros foram realizados no laboratório de informática da escola.

\section{ANÁLISE E DISCUSSÃO DOS RESULTADOS}

Um dos questionamentos feitos aos alunos participantes deste trabalho teve como finalidade quantificar o número de alunos inscritos em alguma rede social e qual o uso destinado a essas redes sociais. Dentre os participantes, $80 \%$ responderam possuir perfil em alguma comunidade virtual e que um dos usos desses ambientes está relacionado a temas escolares.

O SOCRATES foi concebido para ser uma ferramenta de planejamento, execução e acompanhamento de projetos pedagógicos. Então achamos necessário inferir os alunos sobre aspectos positivos e negativos quanto ao uso das ferramentas do AVA. Dentre os aspectos positivos destacamos o fato de ser um ambiente interativo e dinâmico, no qual os alunos se sentiram estimulados a participar das atividades 
propostas. Pires e Veit (2006) defendem a inserção das Tecnologias da Informação e Comunicação como forma de ampliar a interação entre aluno, o conhecimento a ser desenvolvido e o professor, além de ser um importante estratégia para aumentar o tempo de sala de aula, uma vez que o aluno pode realizar as atividades em qualquer ambiente que disponha de uma conexão com a internet.

Dentre as principais dificuldades enfrentadas pelos alunos durante a execução das atividades, 35\% responderam ser a falta de conhecimentos em informática um fator limitante, $32 \%$ colocaram a dificuldade em manusear as ferramentas e outros 18\% a não identificação com as atividades. Ausubel (1968) nos fala que uma aprendizagem significativa está apoiada nos conhecimentos prévios, em material potencialmente significativo e no interesse do aluno.

A primeira atividade desenvolvida no AVA SOCRATES foi um fórum de apresentação do aluno. Segundo Azevedo et al. (2009) fóruns de discussão agregam pessoas com interesses comuns para debater e compartilhar informações. No fórum de apresentação foram estimulados a trocar informações com colegas além de ser uma oportunidade de familiarização com o ambiente. Foi pedido que os alunos escrevessem seus nomes, idade e quais suas expectativas tanto ao início das aulas no ensino médio quanto ao uso das ferramentas do SOCRATES nas aulas de Física.

A análise das participações dos alunos nos fóruns propostos seguiu a proposta de categorização das respostas tendo em vista que seguimos os pressupostos de uma pesquisa qualitativa.

A primeira etapa da análise dos dados foi a leitura de todas as respostas dos alunos. Tivemos o registro de 100 intervenções no primeiro fórum, destinado a apresentação dos alunos e reconhecimento das funções do AVA, no segundo fórum tivemos o registro de 79 respostas, nessa atividade os alunos tiveram a oportunidade 
de debater sobre as diferentes formas de explicar o movimento dos corpos, segundo Aristóteles e Galileu.

A etapa de leitura das respostas dos alunos tem como utilidade a categorização das respostas. Segundo Silva e Fossá (2013) essas categorias possuem caráter pessoal, cada pesquisa e cada pesquisador escolhe as categorias que irá utilizar, essa escolha é baseada na necessidade surgida após a leitura dos dados. Nessa pesquisa as respostas dos alunos foram divididas em dois grupos, aquelas que responderam de forma direta a proposta do fórum e as respostas de interação, ou seja, respostas dadas à fala de outro aluno da turma. Verificou-se que 28 alunos responderam ao fórum de forma direta e que houve um total de 72 mensagens de interação. Extraímos do ambiente duas respostas dadas de forma direta ao que se pedia no fórum:

"Olá pessoal, meu nome é L. e gostei muito dessa comunidade criada pela UFC onde podemos debater com nossos colegas de classe sobre assuntos da matéria e outras curiosidades vlwwwWwWwW. :D" Resposta do aluno L. ao fórum Apresentação.

"Meu nome é J. tenho 13 anos gostei muito desse mei de comunicação entre alunos e professores essa comunidade criada pela UFC é muito legal porque nela nós alunos ou até mesmo professores podem se comunicar um com os outros facilitando os trabalhos e pesquisas que o professor passa pra gente ainda bem que existe esse meio de comunicação porque se não existisse coitadinho da gente ne não vo6 comcordam comigo?" Resposta do aluno J. ao fórum Apresentação.

Em seguida apresentamos duas mensagens de interação entre os alunos.

"L. parabéns por sua inteligência! Mas vc precisa melhorar em se enturmar mais na sala!!! Te dolo rsrsrsrsr!!!!!" Aluno l. em resposta ao aluno L. no fórum Apresentação. 
"Gostei da sua mensagem original. Cresce conforme as oportunidades e nunca desista de seus sonhos. Beijos te adolooo" Aluno B. em resposta ao aluno A. no fórum Apresentação.

Esses trechos mostram que os alunos utilizaram linguagem própria para responder a mensagem, não se preocupando com formalidades gramaticais, o que gera segundo Amaral (2003) apud Ribas et. al (2016) uma preocupação entre os especialistas em linguagem, uma vez que a linguagem adotada no mundo virtual requer uma escrita rápida, o que cria uma solução rápida de comunicação. O aluno J. utiliza a expressão vo6, o que representa não mais uma maneira formal de comunicação e sim um novo símbolo baseado na fonética das palavras.

O segundo fórum proposto, denominado Debatendo o movimento, foi a discussão sobre a teoria do movimento segundo Aristóteles e segundo Galileu. Este assunto foi escolhido por estar presente no currículo da disciplina de Física para a série dos alunos do grupo amostral e por estar elencado num dos temas estruturantes para a Física na $1^{\mathrm{a}}$ série do ensino médio, segundo os PCN's +.

Foi apresentado aos alunos um texto no qual se apresentavam as teorias de Aristóteles e Galileu para o movimento de corpos. Após uma discussão sobre o tema em sala de aula, os alunos teriam que responder no espaço do fórum sobre três questões. O objetivo de tal discussão se baseou em Ausubel (1968), uma vez que é preciso fazer um resgate dos conhecimentos prévios dos alunos para que as novas discussões possam ter onde se ancorar e dessa forma o aluno possa dar significado ao conhecimento que está sendo construído.

A primeira pergunta do fórum questionava sobre o sobre qual das duas teorias, de acordo com seus conhecimentos, seria a mais adequada para explicar o movimento de um corpo. 
A segunda pergunta indagava sobre o que os alunos compreenderam sobre a teoria do lugar natural de Aristóteles e se ela poderia ainda ser aplicada nos dias atuais. Uma vez que muitos alunos têm concepções errôneas ou desconhecem as causas e efeitos de fenômenos físicos ligados ao seu cotidiano, por exemplo, a queda de um objeto.

A terceira pedia que os alunos descrevessem um experimento, de forma simplificada, que eles já tivessem feito ou presenciado, pois no texto apresentado, durante as discussões em sala de aula, mencionava sobre a metodologia de pesquisa desenvolvida por Galileu.

Nesse segundo fórum foi feito o registro de 79 inserções e da mesma forma como aconteceu no fórum de apresentação, o número de respostas de interação foi maior que a quantidade de respostas diretas ao fórum.

Extraímos do AVA algumas inserções registradas pelos alunos. Primeiramente apresentamos duas inserções positivas ao fórum, ou seja, respostas que contemplam as perguntas feitas no início da atividade.

"1. O de Aristóteles o que observava o movimento dos corpos. 2. Na minha opinião eu achei bem interessante por que os quatro elementos são um elemento natural na terra. 3. Bom, eu lembro uma bem legal você mistura coca cola com grosso e logo o impacto do gás com o sal faz com que a bebida cresça." Resposta do Aluno J. ao fórum Debatendo o movimento.

"1. Os dois pois a observação é muito importante mais como Galileu fazia os experimentos fazia com que entendêssemos melhor a concepção do movimento sendo assim o método mais correto. 2. Ele confirmo isso sobre o movimento natural, dizendo que o corpo só seria movimentado por um acontecimento natural ou seja não precisava de nada para se mover, ao contrário do movimento violento. 3. Esperimentos com laranja; com ajuda de uma barbante e duas laranjas amarra as duas no varal; 
movimentando um alaranja a outra irá se mover sozinha, por que existe uma força de energia em ambas." Resposta do aluno D. ao fórum Debatendo o movimento.

Quanto às respostas de interação elas foram maioria, das 79 respostas ao fórum Debatendo o movimento, 45 respostas forma de interação. Em sua maioria concordando com que o colega escreveu ou comentando o experimento citado na questão.

O trecho retirado das participações do aluno J. revela que no seu entendimento a teoria de Aristóteles ainda permanece válida e que ajuda a explicar o movimento dos corpos, pensamento que foi acompanhado por muitos alunos que participaram da atividade. Duas interpretações podem ser dadas a esse fato, o aluno J. foi o primeiro da turma a responder a questão, logo seus colegas podem ter se sentido influenciados pela resposta do colega e acompanharam seu pensamento ou os alunos possuem concepções alternativas sobre movimento dos corpos. Segundo Gravina e Buchweitz (1994) certas concepções são compartilhadas por um número grande de pessoas e são muito resistentes à mudança, mesmo diante do ensino formal.

Neste trabalho o professor atuou como tutor para o uso das ferramentas e na postagem das questões, isto é, não houve por parte do professor de Física uma intervenção nas respostas dos alunos. Cardoso (2003) defende que a participação do professor ou tutor na mediação das discussões é importante para que erros conceituais, interpretações errôneas e até mesmo a defesa de teorias que já foram substituídas, como foi observado em nosso estudo. Esse fato demonstra que nem o computador nem o ambiente SOCRATES sozinhos são suficientes para que o aluno consiga obter êxito na compreensão e na realização das atividades.

No que se refere ao item 3 da questão, a maioria dos alunos participantes do grupo amostral teve uma história a compartilhar. Este fato demonstra certa familiaridade da Ciência ou seu reconhecimento no cotidiano. Frente a essas 
informações o professor pode tomar como estratégia de ensino a inserção de experimentos. Segundo Sèré et. al (2002) o experimento no ensino de Física pode ser utilizada de diferentes formas, dentre elas a maneira mais clássica, na qual o aluno não precisa discutir, somente seguir um roteiro e a junção entre a informática e o experimento na qual o aluno pode testar as várias hipóteses de trabalho com o auxílio das ferramentas computacionais.

Teixeira (2014) cita como vantagens do uso de metodologias de ensino que empregam TDICs, a promoção da independência do aluno, o aumento das fronteiras da sala de aula, o aprofundamento dos conteúdos, a possibilidade de uso em várias plataformas, o despertar o interesse do aluno, dar uma ideia do fenômeno e o fornecimento de feedback.

Observamos que o SOCRATES serviu como meio de propagação da informação, os alunos utilizaram as ferramentas do ambiente para se comunicar. A possibilidade de um local no qual o aluno sinta-se confortável em expor sua opinião faz do SOCRATES um ambiente democrático, no qual é possível discutir sobre vários temas de forma aberta e simples, utilizando as ferramentas que o AVA disponibiliza ao usuário. O ambiente se mostrou um caminho para a desmistificação que a Física é uma disciplina de difícil compreensão e, que segundo Medeiros e Medeiros (2002) pode ser um entrave no ensino e na aprendizagem em Física.

\section{CONSIDERAÇÕES FINAIS}

O computador e a internet fazem parte do cotidiano de muitas pessoas, os avanços tecnológicos dos últimos anos serviram para aprimorar os sistemas computacionais e consolidar o uso dessas ferramentas, destacando áreas como comunicação e produção de material de apoio pedagógico, por exemplo, ambientes virtuais de aprendizagem. 
Dentro do grupo analisado verificou-se que a maioria dos alunos utilizavam redes sociais virtuais, dentre as finalidades estava a troca de informações que dizem respeito a assuntos escolares. Este fato demonstra que a internet vem sendo usada não só como fonte de diversão entre os jovens, mas para construir conhecimentos, com base nas informações coletadas nas redes sociais.

Quanto ao uso do AVA SOCRATES é possível tecer algumas considerações, positivas e negativas. Os alunos destacaram o fato de ser um ambiente que permite o desenvolvimento de atividades que estimulam a aprendizagem. Dessa forma, a inserção do computador como ferramenta metodológica e mais especificamente o uso do SOCRATES pode favorecer a um maior compromisso do aluno para com a realização e entrega de suas atividades escolares.

Mesmo que o uso de ferramentas tecnológicas tenha sido destacado na literatura como uma metodologia capaz de despertar o interesse dos alunos para a aprendizagem em Física, ou seja, promover uma aprendizagem na qual o aluno dê mais significado aos conceitos e distancie a ideia que a Física é uma ciência de resolução de problemas matemáticos, um grupo de alunos do grupo amostral deste trabalho demonstrou desinteresse em participar das atividades propostas. Dentre as justificativas a que mais se destacou foi a não familiaridade com o uso das ferramentas computacionais e uma não identificação com as atividades propostas pelo professor. Mesmo que esse número de alunos tenha sido pequeno, comparado aos que aprovaram o AVA, o professor precisa estar atento para tentar suprir as carências deixadas pelo uso da plataforma.

O ambiente SOCRATES apresentou alguns fatores limitantes, como por exemplo, a falta de ferramentas de formatação textual, a ausência de opções para a publicação de arquivos de multimídia nos fóruns e o número limitado de caracteres no campo destinado ao início dos fóruns, com isso dificultando a compreensão das atividades. 
Não existem no AVA opções para a formatação de texto. A inclusão desses elementos agregaria as respostas, principalmente nos fóruns, um caráter mais pessoal. Embora seja um espaço para a construção de conhecimentos acadêmicos, que requer um certo formalismo gráfico, a inclusão de elementos para a formatação de texto, por exemplo a mudança de fonte, a inclusão de elementos matemáticos e até mesmo a importação de arquivos, pode agregar valor ao ambiente, favorecendo a participação do aluno nas atividades propostas.

A interatividade proporcionada pelos fóruns propostos no SOCRATES foi um dos pontos mais fortes verificados por este trabalho. O SOCRATES se mostrou um canal importante para o debate, oferecendo ferramentas adequadas para a realização das atividades que favoreceram a interação entre alunos e aluno-professor. Embora não existam parâmetros suficientes para medir um aumento na proficiência nas competências e habilidades sugeridas para o ensino de Física, percebe-se nas respostas dos alunos ao fórum a tentativa de um debate.

Assim, com qualquer metodologia de ensino, o professor ou tutor precisa acompanhar o andamento das atividades com a finalidade de auxiliar o aluno na construção do conhecimento. O AVA SOCRATES serviu como uma ponte entre alunos e entre aluno e professor. Uma vez que as atividades podem ser realizadas em casa, a sala de aula é estendida e o tempo que o aluno dedica às atividades é aumentado, com isso espera-se um maior interesse por temas relacionados à Ciência.

\section{REFERÊNCIAS}

ARAÚJO, J.C. Internet e ensino: novos gêneros, outros desafios. Rio de Janeiro: Lucena, 2007. 282 p.

AUSUBEL, D. P. Educational Psychology: A Cognitive View. New York: Holt, Rinehart and Winston, 1968. 
AZEVEDO, B.F.T et. al. Estudo de análise qualitativa em fórum de discussão. Novas tecnologias na educação, v.7, n. 3, p. 135-145, 2009.

CARDOSO, N. L. A utilização do software educacional de simulação e modelagem "Interactive Physics" como instrumento de promoção da aprendizagem significativa de conceitos de Física: uma investigação pedagógica a partir da proposição de situações-problema". Dissertação (Mestrado em Ciências da computação) Florianópolis: UFSC, 2003. 111f.

COSTA, R. da. As comunidades virtuais. Informática na educação: teoria \& prática, v. 8, p. 55-74, 2005.

DIAS, C. A. Hipertexto: evolução histórica e efeitos sociais. Ciência da Informação, v.28 p.269 - 277, 1999.

FILHO, C.F. História da Computação: o caminho do pensamento e da tecnologia. Porto Alegre: EDIPUCRS, 2007. 205 p.

GRAVINA, M. H., BUCHWEITZ, B. Mudanças nas concepções alternativas de estudantes relacionadas a com eletricidade. Revista Brasileira de Ensino de Física, v. 16 p. 110 119, 1994.

LÉVY, P. As tecnologias da inteligência. 34 ed. Rio de Janeiro: 34, 2000. 264 p.

MEC (2002). PCN + Ensino Médio: Orientações complementares aos Parâmetros Curriculares Nacionais. Brasília: SEMTEC, 2002. 144 p.

MEDEIROS, A.; MEDEIROS, C. F. Possibilidades e limitações das simulações computacionais no ensino de física. Revista Brasileira de Ensino de Física, v. 24, n. 2, p. 77_85, Junho 2002. 
PIRES, M. A.; VEIT, E. A. Tecnologias da informação e comunicação para ampliar e motivar o aprendizado de física no ensino médio. Revista Brasileira de Ensino de Física, v. 28, p. 241_2248, 2006.

RIBAS, E. et. al. A influência da linguagem virtual na linguagem formal de adolescentes. Disponível em <http:// http://www.cinted.ufrgs.br/ciclo9/artigos/8dElisangela.pdf> Acesso em ago. 2016.

SÈRÉ, M.G. et al. O papel da experimentação no ensino de Física. Caderno Brasileiro de Ensino de Física. v. 20 n. 1, p. 30-42, 2002.

SILVA, M. A. dá et al. Criação e acompanhamento de projetos colaborativos no ambiente SOCRATES. In: XXVII Congresso da SBC. [S.I.: s.n.], 2007.

SILVA, A. H.; FOSSÁ, M. I. T. Análise de conteúdo: exemplo de aplicação da técnica para análise de dados qualitativos. In: Encontro de Ensino e Pesquisa em Administração e Contabilidade, 4., 2013, Brasília. Anais. Brasília: IV Encontro de Ensino e Pesquisa em Administração e Contabilidade, 2013, p. 1 - 14.

TEIXEIRA, G.G.S. As TDIC na formação inicial de professores de Física: a voz dos egressos e licenciandos do curso. Dissertação (Mestrado em educação científica e tecnológica). Florianópolis: UFSC, 2014. 137f.

YIN, R. K. Estudo de caso: planejamento e métodos 2 ed. Porto Alegre: Bookman, 2001. 